\title{
Formação em pesquisa na pós-graduação: possibilidades e desafios a partir da orientação
}

\section{Research Training in Postgraduate: possibilities and challenges from orientation}

\author{
Maria de Fatima Quintal de Freitas* \\ Jusamara Souza**
}

\begin{abstract}
RESUMO
O debate a respeito da Pós-Graduação stricto sensu no Brasil tem focalizado a questão da qualidade no processo de produção de conhecimento, em especial a partir dos três últimos Planos Nacionais da Pós-Graduação. Considerar este tema significa também levar em conta os aspectos relativos às condições objetivas e subjetivas dos trabalhos na pós-graduação. $\mathrm{O}$ artigo discute as relações entre pesquisa, formação e produção de conhecimento presentes no trabalho de orientação, nos cursos de pós-graduação stricto sensu. Foram registradas, sistematizadas e submetidas a uma análise qualitativa, informações oriundas de orientações realizadas no período de 1995 a 2017, ao nível de mestrado e doutorado, em Programas de Pós-Graduação em Educação, Educação Musical e Psicologia. Foram analisadas as relações entre as condições objetivas de desenvolvimento do trabalho na pós-graduação e os impactos na formação dos pós-graduandos através da pesquisa. São tecidas considerações sobre os efeitos psicossociais gerados no processo de orientação, que podem afetar, positiva ou negativamente, não só a produção de conhecimento como também a qualidade das interações nesse tipo de atividade. São feitas algumas reflexões sobre uma agenda que considere o ofício da orientação como um processo, também, de formação.
\end{abstract}

Palavras-chave: Orientação na pós-graduação. Formação na pós-graduação. Pesquisa e pós-graduação.

* Universidade Federal do Paraná. Programa de Pós-Graduação em Educação. Curitiba, Paraná, Brasil. E-mail: fquintal@terra.com.br. https://orcid.org/0000-0002-0414-199X.

** Universidade Federal do Rio Grande do Sul. Programa de Pós-Graduação em Música. Porto Alegre, Rio Grande do Sul, Brasil. E-mail: jusa.ez@terra.com.br. https://orcid.org/00000001-6392-3951 


\begin{abstract}
The debate regarding the stricto sensu Post-Graduation in Brazil has focused on the subject of quality in the process of knowledge production, especially after the last three National Postgraduate Plans. Considering this topic also means taking into account the aspects related to the objective and subjective conditions of the postgraduate work. The article discusses the relations among research, formation, and production of knowledge that are present in the orientation work in stricto sensu postgraduate courses. Information collected from 1995 to 2017, at Masters and PhD levels, in Postgraduate Programs in Education, Music Education and Psychology were recorded, systematized, and submitted into a qualitative analysis. The relations between the objective conditions of postgraduate work development and the impacts on postgraduate training through the research were analyzed. Considerations are made about the psychosocial effects generated in the orientation process, which can affect positively or negatively not only the production of knowledge but also the quality of the interactions in this type of activity. There are some reflections about an agenda that considers the work of orientation also as a process of formation.
\end{abstract}

Keywords: Postgraduate orientation. Postgraduate training. Research and postgraduate.

\title{
Introdução
}

A expansão da pós-graduação no Brasil, que se acentua em especial a partir de meados dos anos 1990 (BARRETO; DOMINGUES, 2012), trouxe para o debate científico não apenas a análise sobre os produtos obtidos, com as inúmeras teses e dissertações concluídas, como passou também a mostrar a importância de que as condições dessa produção do conhecimento sejam analisadas. Entre tais condições destacam-se aquelas que dizem respeito: a) ao impacto da precarização do trabalho intelectual-acadêmico (KUENZER; MORAES, 2005); b) aos fatores que potencializam o adoecimento no ensino superior na pós-graduação (MAUÉS, 2016; RUZA, 2017); c) aos desafios na formação de pesquisadores e docentes no ensino superior dirigido à produção de conhecimento (BIANCHETTI, 2012; BONADIMAN; ROMAGNOLI, 2017; ARAUJO, 2015); e d) às dimensões psicossociais presentes no processo de orientação de trabalhos científicos na pós-graduação stricto sensu (MANCEBO, 2007). 
Muitos são os trabalhos que têm se proposto a analisar a pós-graduação, sob diferentes perspectivas, desde uma óptica mais microssocial até uma visão mais abrangente. Na tarefa de ampliação e internacionalização das redes de investigação da pós-graduação, a exigência, cada vez mais intensa, de publicações em pouco tempo para sua gestação tem se constituído em grande desafio para a qualidade da docência e da pesquisa e, consequentemente, da produção de conhecimento nesse âmbito. Este caráter altamente produtivista na pós-graduação tem trazido para o debate algumas questões como: que parâmetros considerar para dimensionar a qualidade das pesquisas e seus produtos; que aspectos influenciam e avalizam a abrangência dos resultados obtidos; que implicações existem entre o caráter inovador em ciência e os inúmeros e repetidos trabalhos científicos. Embora o foco deste artigo não seja aprofundar essas discussões, considera-se que elas são importantes para uma reflexão sobre a relação entre qualidade e inovação dos trabalhos científicos e do impacto social, de um lado, e sofisticação técnica e aprofundamento teórico, de outro.

A proposta deste artigo está em analisar as relações entre as condições objetivas de produção do conhecimento e trabalho docente na universidade, e as condições subjetivas como as dimensões psicossociais que emergem das interações presentes no processo de orientação na pós-graduação stricto sensu. Assim, buscam-se analisar as dimensões subjetivas e psicossociais presentes no exercício do trabalho do(a) docente-pesquisador(a) e pesquisador(a)-docente e que podem interferir na continuidade e qualidade das atividades.

Para isso, este estudo foi conduzido com base em informações obtidas ao longo de uma investigação de caráter longitudinal que cobriu o período de 1994 a 2018, e que foram registradas por meio de observações participantes, de registro documental a respeito dos processos de mediação na orientação, e dos registros da história oral dessas mediações e interações. Foi possível reunir informações relativas aos trabalhos de orientação, às interações individuais e coletivas no âmbito da formação na pós-graduação, desenvolvidos junto aos mestrandos(as) e doutorandos(as) em programas de pós-graduação stricto sensu, em Educação Musical, Educação e Psicologia, em universidades públicas de duas regiões do Brasil.

Nas seções seguintes, serão apresentadas reflexões sobre: os Planos Nacionais de Pós-Graduação, elaborados desde 1975; o contexto e as dimensões psicossociais da relação orientadores-orientandos indicando paradoxos vividos; proposições para pensarmos à docência e à investigação na pós-graduação, assim como a formação de quadros para a produção de conhecimento. 


\section{Os Planos Nacionais de Pós-Graduação}

A ampliação da pós-graduação no Brasil aconteceu também como resultado da reforma na educação superior no país, divulgada nos vários Planos Nacionais da Pós-Graduação - PNPG (AZEVEDO; OLIVEIRA; CATANI, 2016; HOSTINS, 2006). Estes planos, por sua vez, compõem o "Plano Nacional de Educação, de responsabilidade do MEC e de cuja estrutura a CAPES integra, devendo [o PNPG] em princípio estar coordenado ao instrumento maior que visa o [sic] sistema de educação como um todo" (BARRETO; DOMINGUES, 2012, p. 18). Dessa forma, as políticas de Estado voltadas à educação em geral, também produziram impactos nos planos específicos a cada nível de ensino, decorrentes também da conjunção de forças políticas e econômicas de cada período, como é o que se verifica nos seis PNPG pelos quais a pós-graduação no Brasil já passou.

O primeiro PNPG (1975-1979), criado em plena ditadura militar, tinha como meta formar especialistas no âmbito da docência, pesquisa e atuação técnica também para o parque industrial brasileiro. Com isso, a meta foi ampliar o sistema nacional de pós-graduação que era, à época, reduzido e tinha de recorrer a quadros de pesquisadores trazidos do exterior (BRASIL, 2005). Essa exigência revelou um forte paradoxo, vivido no seio da universidade: de um lado, os docentes e pesquisadores foram chamados a colaborar com um Estado autoritário que lhes exigia resultados "desenvolvimentistas" como cientistas e produtores de conhecimentos sendo apoiados em suas pesquisas; e, de outro, na condição de cidadãos e pesquisadores, comprometidos com a realidade nacional, não podiam se expressar ou combater o regime de exceção, ameaçados pelo risco da perda de apoio às suas pesquisas e/ou pelo "convite" a viverem no ostracismo em outros países (HOSTINS, 2006; RIBEIRO, 2016).

O PNPG II (1982-1985) surgiu já no período da transição democrática, privilegiando reflexões e estratégias que fortalecessem a avaliação na pós-graduação, o que trouxe para o debate a preocupação para com a qualidade das produções científicas no âmbito da universidade (BRASIL, 2005).

O período de 1986 a 1989 é o relativo ao III PNPG, que mesmo enfatizando uma integração de vários campos da ciência e pós-graduação no Brasil, revelou mais explicitamente os impactos e prejuízos na universidade brasileira das precariedades socioeconômicas pelas quais o país passava (BARRETO; DOMINGUES, 2012). O alto custo de vida, juntamente com a depreciação de salários e instabilidade de empregos, também manteve a universidade em um cenário de parcos recursos para as pesquisas, com escassez de produção e qua- 
lificação, ao lado de uma insegurança nas atividades de docência e pesquisa, e que ainda se refletiram na irregular e inconstante produção científica e formação de novos quadros de cientistas.

Em um seminário promovido pela CAPES, em 1996, com a finalidade de discutir a pós-graduação brasileira, foram feitos debates que resultaram na produção de documentos que viriam a constituir-se como base para o IV PNPG (RIBEIRO, 2016; BRASIL, 2005) relativo ao período de 1990 a 2002. Embora este documento não tenha se tornado público e nem sido institucionalizado, ficando restrito somente às agências CAPES e $\mathrm{CNPq}-\mathrm{e}$, por isso, não foi considerado por muitos estudiosos como sendo um PNPG - suas diretrizes acabaram, guiando de algum modo a pós-graduação nos anos seguintes. Esse foi um período longo com variadas influências governamentais e políticas, mostrando diferentes interesses quanto à educação e à pós-graduação. Em um documento de 2010, referente ao PNPG VI, de 2010, há a indicação de que aqueles documentos, resultantes das discussões acontecidas em 1996, passaram então a ser considerados como compondo um plano para a pós-graduação (BRASIL, 2010). Constituíram-se, então, como diretrizes do PNPG IV e passaram a indicar as seguintes ações: diversificação do modelo da pós-graduação, do seu processo de avaliação e da sua inserção internacional bem como a implementação de estratégias para ampliar o sistema da pós-graduação (BRASIL, 2010).

O V PNPG (2005-2010) apoia-se nas diretrizes presentes nos dois governos Lula (2003-2006 e 2007-2010), que enfatizaram a educação pública incluindo a ampliação e a interiorização das universidades e seus quadros. Esse Plano apresenta propostas para uma pós-graduação que já se encontra mais madura, com ações que vão se consolidando em torno de estratégias e de conteúdos de avaliação (BARRETO; DOMINGUES, 2012; RIBEIRO, 2016).

A ideia de produção científica submetida à marca da produção mercadológica, em que o mercado se constitui como matriz regulador do trabalho científico (SILVA JÚNIOR; SGUISSARDI, 2012, 2013), aparece fortemente no VI PNPG (2011-2020), embora tais bases tenham sido lançadas já em planos anteriores. Essas características também aparecem em propostas internacionais para a pós-graduação, por exemplo, na Europa, com o Processo Bolonha que é considerado o modelo europeu dessa ênfase produtivista e mercadológica, com vistas à regulação dos produtos e processos da pós-graduação.

Ao longo dos anos dos vários PNPG, a ênfase na produção da pós-graduação como sendo um elemento central, seja para sua consolidação no âmbito nacional e internacional, seja para garantir índices mais altos de qualificação dos pesquisadores para o quadro científico-tecnológico do país, trouxe um cenário 
[...] contraditório: um verdadeiro surto produtivista em que o que conta é publicar, não importa qual versão requentada de um produto, ou várias versões maquiadas de um produto novo. A quantidade institui-se em meta. Deste modo, formas legítimas de produção, como coautorias e organizações de coletâneas - em inúmeros casos produtos de sólidas pesquisas integradas -, banalizaram-se no âmbito de algumas áreas de conhecimento, entre elas a Educação (KUENZER; MORAES, 2005, p. 1348).

Essa faceta relativa à exigência de mais produtos bibliográficos, já discutido em vários estudos (ARAUJO, 2015; CAFÉ; RIBEIRO; PONCZEK, 2017; LEITE, 2017), tem gerado uma frenética competição por periódicos mais "disponíveis" para publicação. Isso tem colocado, muitas vezes, em segundo plano, a adequação desses veículos quanto ao quesito pertinência ao tema e público-alvo a quem se destina a pesquisa realizada. Além disso, há também outro aspecto que fortalece esse clima de competição e que concorre com a qualidade das produções geradas. Trata-se do tempo considerado adequado para a realização dos estudos de pós-graduação, ao nível do mestrado e doutorado, incluindo nesse tempo a realização das disciplinas mínimas necessárias, o processo de orientação, o desenvolvimento da pesquisa, a confecção e a redação da dissertação ou tese e, no mínimo, a geração de um produto bibliográfico, de preferência, já aceito para publicação.

Apresentado esse contexto mais amplo das políticas brasileiras para a pós-graduação, representadas pelos Planos Nacionais, a seguir serão discutidos os efeitos psicossociais gerados no processo de orientação, que podem afetar, positiva ou negativamente, a produção de conhecimento e a qualidade das interações orientador-orientando, nesse tipo de atividade.

\section{O contexto da problemática estudada}

O ofício da orientação congrega dimensões, nem sempre harmônicas entre si, ainda mais se considerarmos o cenário sociopolítico no qual a pós-graduação no Brasil está, atualmente, inserida. Essas dimensões apontam, de imediato, para uma díade que está apoiada na atividade de pesquisa e na atividade de docência. Entretanto, dada a própria especificidade dessa atividade no âmbito da pós-graduação, deparamo-nos com uma outra subdivisão, agora, em, conteúdos opostos, ou seja: aquela, a pesquisa, deve ser conhecida e entendida em uma amplitude extrema que possa abarcar o maior número de variedades e desdobramentos 
sobre o seu fazer; e esta, a atividade de docência, adquire uma particularidade sobre o ensinar (o quê e como) que se remete diretamente às características de cada um dos seus destinatários, ou seja, os orientandos.

Em outras palavras, parece que cabe ao orientador congregar em si, ao mesmo tempo, uma postura contraditória. De um lado, deve ser "amplo e profundo", no sentido de ter um domínio abrangente de conhecimentos, habilidades e know how no campo da pesquisa que lhe permita dominar inúmeros e variados caminhos epistemológicos que apresentará aos seus orientandos para desenvolver o trabalho na pós-graduação. De outro, deve ter um olhar sensível e dirigido ao "miúdo do cotidiano" (SOUZA, 2005), a ponto de perceber as mínimas e contundentes necessidades dos orientandos quanto às estratégias e caminhos importantes para a aprendizagem naquele fazer pesquisa, específico àquele objeto de estudo. Como Souza et al. escrevem:

Considerando que o orientador se dedica à orientação de temas vinculados à sua própria linha de pesquisa, essa tarefa exige, além das habilidades tradicionais para se fazer pesquisa, habilidades pedagógicas e gerenciais ou administrativas da pesquisa, que, ao serem compartilhadas, potencializam suas possibilidades de aprofundamento, ao mesmo tempo, que tal vivência torna-se um exemplo de como se pode trabalhar em grupo na construção do conhecimento.[...]A experiência mostra que, constituídos como um grupo de pesquisa, os pós-graduandos podem trocar informações com colegas mais experientes, explicitar e comparar seus métodos de trabalho (SOUZA et al., 2005, p. 7).

Se essas considerações tiverem alguma razão, caberia então perguntar: como se chegaria a este "tipo" de orientador(a)? Ou, de outro modo, haveria condições e um tempo mínimo que seriam necessários para a sua constituição como orientador(a)? E, nessas condições, como se estabeleceria a relação com os orientandos e que desafios enfrentaria para alcançar a meta de formar pesquisadores(as) na pós-graduação?

Essas são algumas questões que foram se construindo ao longo dos vários processos de orientação, no âmbito do mestrado e doutorado. As informações reunidas aqui se referem aos processos de orientação ocorridos em três universidades públicas, duas na região Sul e uma na região Sudeste, no período de 1994 a 2017. Consideraram-se os processos de orientação concluídos, ou seja, que resultaram em teses e dissertações finalizadas. Na área de educação e psicologia, foram 28 no mestrado e 12 no doutorado; e, na área de educação musical, foram 23 de mestrado e 23 no doutorado. 
A cada sessão de orientação, ao longo desses anos, foram feitas anotações e registros individuais datados que reuniam informações sobre o que acontecia na orientação, como: atividades e tarefas apresentadas com esclarecimento de dúvidas teóricas, metodológicas ou ambas; sugestões e encaminhamentos de estudos e leituras consideradas necessárias para a perspectiva teórica e/ou metodológica; elaboração e proposição de planos estratégicos para revisão bibliográfica, (re) elaboração e checagem de objetivos da pesquisa; o que fazer e como atuar no campo empírico; como elaborar a seção teórica, orientações passo a passo para a construção do marco teórico; discussão e estruturação das seções de resultados e discussão; cuidados e discussões éticas ao longo da pesquisa, entre outras. A cada uma dessas atividades havia um registro não somente da tarefa em si, seja realizada seja solicitada, mas também das dificuldades percebidas sobre o desempenho dos orientandos, quanto das dificuldades relativas a como ensinar tais tarefas ou caminhos para o fazer pesquisa, que não fosse de modo reprodutivista e autômato, e que pudesse ser absorvido como um processo pedagógico por eles para atuação futura como docente e pesquisador.

Em vários momentos desse processo de pesquisa, havia alguns pontos de inflexão e de desafios à orientação. Nesses momentos, a discussão teórico-metodológica e sobre o processo maior relacionado à produção de conhecimento estampavam a necessidade de um conhecimento que ultrapassasse os limites do objeto de pesquisa em questão. Ou seja, apresentava-se como necessidade o domínio, por parte das orientadoras, de alguns conhecimentos e habilidades relativos ao fazer pesquisa, ao analisar a realidade e ao circunscrever o objeto de investigação em um cenário e contexto sociopolítico-ideológico-filosófico de âmbito maior.

\section{Impactos no processo de orientação}

Independentemente das informações reunidas, nesta pesquisa, situarem-se em áreas disciplinares diferentes, as condições objetivas e subjetivas de realização do trabalho na pós-graduação têm impacto sobre como se deu e como vem sendo construída a relação orientador e orientando.

As condições objetivas e subjetivas do trabalho de orientação produziram efeitos na decisão e na definição de três aspectos, a saber: o conteúdo temático da pesquisa, o ritmo do trabalho a ser desenvolvido, o modo de organizar o trabalho. Essas decisões implicaram na constituição de um processo interacional vivido entre orientadoras e orientandos, que contribuiu para a construção de um produto final cujas características derivam desses efeitos e impactos 
gerados ao longo da pós-graduação. Uma interdependência desses aspectos está apresentada na Figura 1.

\section{FIGURA 1 - DIMENSÕES PSICOSSOCIAIS PRESENTES NO PROCESSO DE ORIENTAÇÃO}

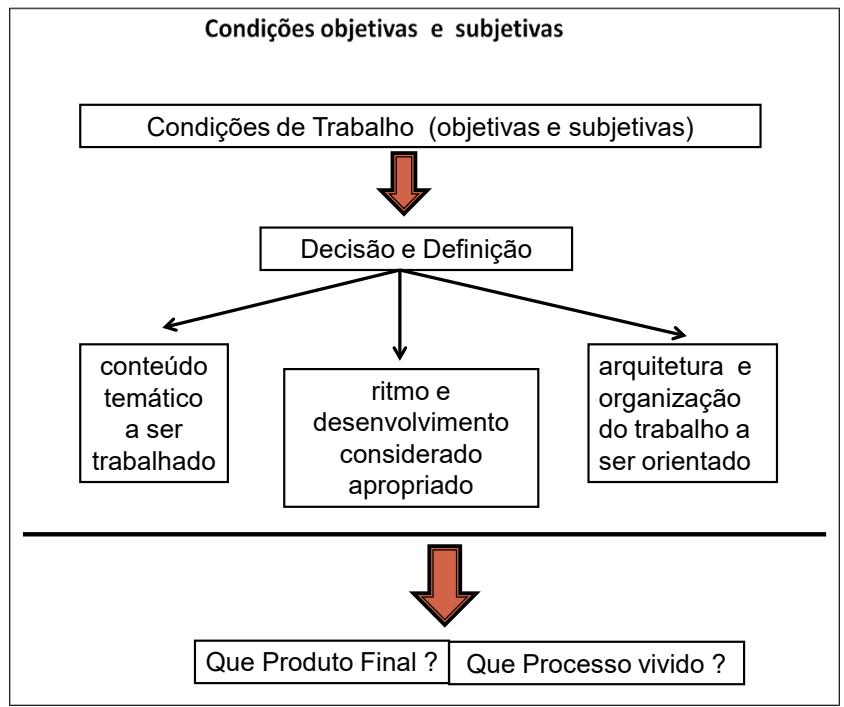

FONTE: as autoras, 2018.

Essas dimensões psicossociais, presentes nesses três aspectos e que interferem na realização do trabalho de orientação, são detalhadas a seguir.

Quanto ao modo de definir, selecionar e circunscrever o conteúdo temático do trabalho a ser orientado, para cada um dos orientandos, poder-se-ia dizer que, embora com caminhos estruturais semelhantes, cada proposta de pesquisa constituiu-se em um arcabouço investigativo e epistemológico único e singular, planejado, desenhado e com uma arquitetura construída pelo olhar experiente e cumulativo da orientação. Encontrou-se, aqui, o ofício de orientador naquelas características artesanais já apontadas por Mills (2009).

Com relação à tomada de decisões sobre o ritmo, considerado apropriado, das atividades e do desenvolvimento do trabalho, alguns indicadores foram se mostrando importantes nessa interação orientadoras-orientandos, como:

a) materialização da confiança recíproca nas relações de orientação;

b) valorização e reconhecimento da autoridade intelectual-acadêmica da orientação no processo de formação de pesquisadores versus interesse precípuo na aquisição do título; 
c) melindres e concepções errôneas a respeito da autoria e "propriedade" do trabalho final, quando deixam de perceber que se trata de um trabalho dialeticamente colaborativo, em que ambos - orientandos e orientadoras - foram instados pelo outro a gerar produtos metodológicos e teóricos sobre o objeto de estudo construído em parceria intelectual;

d) existência anterior de conhecimentos e habilidades, por parte do orientando, relacionados ao tema;

e) domínio de conhecimentos anteriores e a utilidade dos mesmos para um adequado desempenho acadêmico no campo da investigação;

f) detectação de (in)coerência e (in)consistência entre habilidades verbais e escritas (linguagem oral e escrita), entre linguagem coloquial, literária e linguagem científica cujas características são bem diversas;

g) identificação de modo apropriado da resistência à frustração, por parte dos pós-graduandos, e sua adequação às (não) habilidades sociais para lidar com isso;

h) presença de características de personalidade positiva e atitudes proativas diante das críticas e feedbacks negativos, e da necessidade de mudanças e reformulações no curso da pesquisa.

Quanto aos impactos na arquitetura e na organização do trabalho a ser orientado e desenvolvido, com vistas ao seu produto final, dois aspectos surgiram como decisivos. O primeiro refere-se às condições de aprendizagem e de trabalho dos orientandos que possam contribuir para uma maneira eficiente de produzir conhecimento, tendo qualidade e profundidade, assim como as condições subjetivas para desenvolver o trabalho, de um modo eficaz, sem perder o foco e evitando atalhos dispendiosos e dispersivos. O segundo aspecto, relativo ao modo de organização do trabalho, dirige-se, especificamente, às condições de realização do próprio trabalho de pesquisa. Nisto têm se mostrado importantes as seguintes dimensões:

a) que o foco do estudo deve ser mantido;

b) que o processo de realização do trabalho dentro do que foi planejado pelo orientador deve ser, consistente e eticamente preservado;

c) que o resultado final (tese/dissertação, livro/capítulos e publicações em periódicos sob a forma de artigos) possa espelhar, com justeza e honestidade, o processo, o produto e a participação compartilhada entre orientadores e orientandos.

Todas essas reflexões deveriam valorizar o papel intelectual e participativo da orientação no trabalho de pesquisa, colaborativa e compartilhada, que é de- 
senvolvido ao longo desse processo. Isso deveria acontecer sem se cair em um discurso de "doação cristã", ou seja, de que caberia ao orientador sacrificar-se, a qualquer custo, para garantir o "trabalho do aluno" (grifo nosso). Em uma perspectiva histórica das condições objetivas desse processo na pós-graduação, verifica-se que isso não corresponde à realidade; observa-se que a proposta inicial apresentada pelo candidato, quando do processo seletivo ao mestrado ou doutorado, é estruturalmente distinta da produção final construída e apresentada no momento da defesa.

Soma-se a isso "a inexperiência em pesquisa, articulada à não rara fragilidade da formação teórica anterior", o que, segundo Kuenzer e Moraes (2005), "demandaria um tempo maior para o amadurecimento acadêmico de grande parte dos alunos." Como as autoras analisam:

[...] os programas de pós-graduação assumiram como meta titular de qualquer forma e a qualquer custo - em 24 ou 48 meses. Neste processo, as condições reais de trabalho dos alunos passaram a segundo plano. $\mathrm{O}$ percurso curricular confrangido supõe um aluno idealizado - de modo preferencial os que trazem experiência de bolsas de iniciação científica - com suficiente autonomia intelectual para dominar as categorias teórico-metodológicas em um ano, e com condições para finalizar a "pesquisa" ao final do segundo ano, admitida uma extensão de mais seis meses de prazo para os não bolsistas. (KUENZER; MORAES, 2005, p. 1349).

Uma estratégia pedagógica e formativa seria os orientadores fazerem exercícios comparativos, em suas disciplinas e seminários públicos, de metodologia de pesquisa, entre a proposta inicial apresentada pelo pós-graduando ao ingressar no curso e a primeira, segunda, terceira e, enfim, últimas versões. Essas versões são lapidadas em um trabalho conjunto com o orientador que, ao articular e desenhar uma complexa arquitetura epistemológica da investigação, conduz o pós-graduando por um caminho teórico-metodológico reconhecido. Vai se materializando, assim, a relação dialética entre ambos.

Até o momento deu-se destaque às repercussões dessas condições na pesquisa desenvolvida e nos pós-graduandos, durante o processo de orientação. Entretanto, esses mesmos fatores e situações também afetam a vida e o trabalho dos orientadores, quanto à organização e ao ritmo de suas atividades profissionais e pessoais. Essa dinâmica de repercussões está apresentada na Figura 2. 
FIGURA 2 - EFEITOS E IMPACTOS PSICOSSOCIAIS SOB A ÓPTICA DO(A) ORIENTADOR(A)

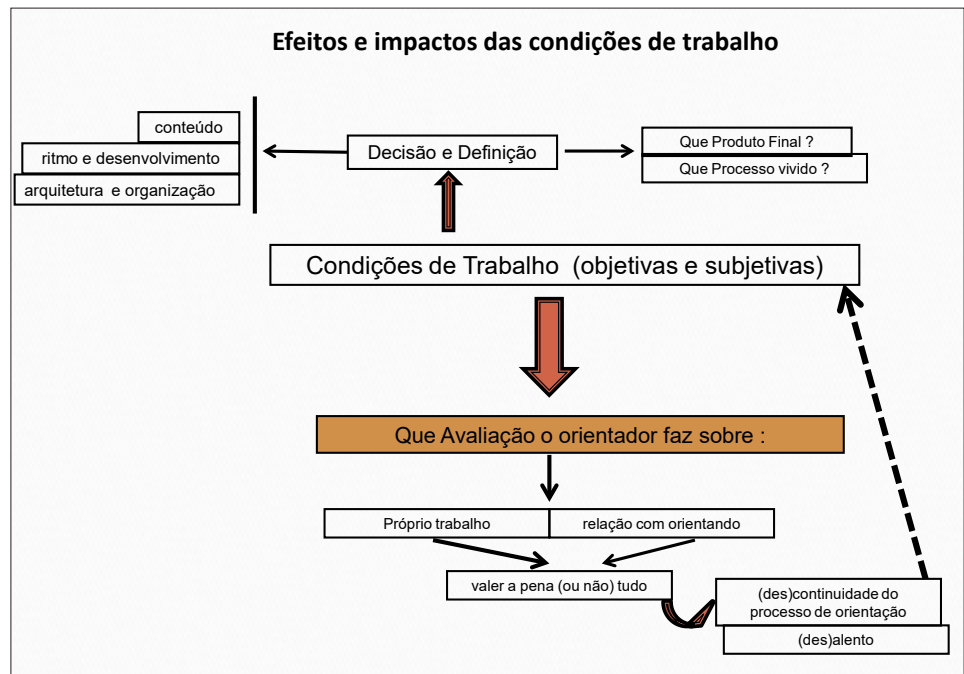

FONTE: as autoras, 2018.

Além de caber ao orientador enfrentar as tensões e dúvidas relativas ao processo de decisão sobre o conteúdo da temática, ritmo e desenvolvimento da pesquisa, arquitetura e organização desta, também se depara com tensões e conflitos relativos às avaliações intrínsecas que seu trabalho demanda continuamente. Esses questionamentos dirigem-se ao próprio trabalho e à relação com os orientandos, em termos de avaliar se vale a pena (ou não) haver a (des)continuidade na orientação, o que implica, por sua vez, em formas de (des)alento quanto ao trabalho realizado. Estabelece-se assim um círculo entre essas dimensões objetivas e subjetivas que podem interferir no andamento do trabalho, assim como podem levar a situações de tensão e dúvidas, que geram graus diferenciados de sofrimento psicossocial com relação ao processo de orientação, à proposta do trabalho, aos resultados alcançados e às demandas de formação que são construídas na pós-graduação.

\section{Algumas considerações}

A sistematização e análise de caráter qualitativo desses registros individuais, aliada ao objetivo deste trabalho - de compreender os desafios e dilemas 
que surgem nessa interação construída de maneira processual e dialógica, em que tensões e dificuldades de ordem acadêmica, profissional e pessoal aparecem ao longo dos dois anos (no caso dos mestrados) ou dos quatro (no dos doutorados) anos de trabalho conjunto - permitiram uma compreensão sobre as dimensões psicossociais presentes nessa (inter)subjetividade compartilhada entre orientador e orientando.

Pôde-se observar que essas tensões, dificuldades e pontos de inflexão acentuaram-se, nos últimos anos, visto que houve um acirramento das pressões do sistema de pós-graduação na cobrança de um número maior de produtos em um tempo que seja cada vez mais eficiente quantitativamente.

Esse impacto prejudicial do tempo reduzido sobre a profundidade e a qualidade dos trabalhos finais, em especial, no mestrado, são também indicados por Kuenzer e Moraes (2005), que agregam também a dificuldade de serem cursadas disciplinas e seminários que contribuiriam para uma formação ampliada no campo das ciências humanas e sociais.

Considerando-se que essas condições objetivas produzem um forte impacto no modo como o trabalho é realizado entre esses dois atores sociais - orientando e orientador - poderíamos fazer aqui um recorte para pensar alguns aspectos presentes nessa relação da orientação.

Assim, pode-se dizer que a análise das dimensões psicossociais aponta para a necessidade de que as atividades desenvolvidas no processo de orientação sejam também (re)conhecidas dentro de outro paradigma na relação trabalho-produto-processo. De um lado, isso significaria "desnaturalizar" concepções que associem e valorizem o trabalho da orientação como tendo marcas de "cuidado e generosidade", com traços de uma certa maternagem, doação e voluntariado. De outro, com relação aos orientandos, seria importante conhecer as condições objetivas que estes têm para se envolverem com as diferentes atividades e demandas na pós-graduação, além de serem identificados os domínios teóricos e metodológicos que já apresentam sobre o processo de fazer pesquisa e produzir conhecimento.

A manutenção de visões naturalizantes e parciais sobre essas dinâmicas, em nosso entendimento, contribuiria para escamotear as precárias condições de trabalho que acabam por legitimar o produtivismo acadêmico. Valorizar isso reforça a falsa ideia de que maior produtivismo corresponderia a melhores possibilidades de ascensão na carreira, em detrimento da necessidade de qualidade e da produção de conhecimentos socialmente relevantes e comprometidos com a realidade nacional e local.

Nesse embate, muitas vezes, a ênfase colocada em dimensões pessoais da relação orientador-orientando, para explicar o sucesso ou fracasso do trabalho realizado, surge como um elemento que pode distorcer o significado psicossocial 
das condições de trabalho. Isso acontece quando as razões do sucesso ou fracasso do trabalho - em termos de qualidade, complexidade, eficiência, relevância, aplicabilidade e contribuição com a área de investigação - são deslocadas para motivos pessoais, deixando de levar em conta as reais condições que podem facilitar ou dificultar a realização do trabalho durante a pós-graduação. Entre tais condições reais, encontramos em relação à perspectiva dos orientandos, por exemplo, o pouco conhecimento e familiaridade sobre pesquisa e escrita científica; o pouco tempo para estudos dirigidos e a participação em outras disciplinas, em especial se eles não forem bolsistas; baixas condições para realizar formações paralelas como domínio de aplicativos em pesquisa e da língua estrangeira; entre outras. Em meio as condições reais que impactam sobre o trabalho realizado pelos orientadores, podem ser citadas: aumento dos seus papéis na orientação, tendo de assumir muitas vezes o papel de "corretor linguístico" antes mesmo do de analista e debatedor de ideias e propostas de pesquisa no plano de investigação realizado; exigência aumentada de produções bibliográficas com alto Qualis; aumento nas atividades paralelas como parecerista e membro de comitês científicos, entre outras.

A esse respeito, considerando o ofício de ser também professor, Freitas (2003) apresenta alguns questionamentos que põem em destaque as dimensões psicossociais que poderiam contribuir para a compreensão dos dilemas e tensões vividos no cotidiano do professor, que aqui também poderíamos estender ao docente da pós-graduação,

[...] aquelas indagações [...] sobre o que os docentes devem saber e conhecer, sobre o que devem escolher para ensinar, como devem ensinar e como saber que seus alunos aprenderam - passam a ter a dimensão dos processos psicossociais que perpassam a rede de relações do professor. Em outras palavras, elas deixam de ter os aspectos meramente funcionais e pedagógicos, e passam a colocar o docente, como ator psicossocial fundamental, no centro desta análise. Que significado e que sentido sua ação cotidiana, materializada nas relações travadas nessa dinâmica ensino-aprendizagem, tem para ele? Que certezas e que dúvidas vai construindo a respeito do seu papel e da importância sobre o que faz e que alternativas de solução vai conseguindo encontrar para que, tanto ele quanto os outros sociais, estejam a se beneficiar do processo e do produto de seu trabalho? Como têm sido alimentadas as crenças sobre estar valendo a pena o seu trabalho, e que contribuições ele tem produzido para além de ganhos imediatos e pessoais? (FREITAS, 2003, p. 146-147). 
Esses são aspectos que também mereceriam ser considerados em propostas pedagógicas que considerem o ofício de ser orientador como uma atividade que deveria receber formação pedagógica e científica específica. A docência como elemento presente e imanente às tarefas de pesquisa na pós-graduação pouco tem sido considerada, merecendo ser alvo de programas de formação que considerem a pós-graduação também como uma instância formativa. A aprendizagem do tornar-se orientador ainda tem acontecido como resultado de trajetórias pessoais com os próprios orientadores, por modelação, por experiências de eliminação do que foi vivido negativamente, ou até por formas de (re)afirmação de sua autoridade, entre outras maneiras.

Considerar a pós-graduação como uma instância fundamental na universidade, também requer que sejam pensados formas e planos de preparação e formação pedagógica e psicossocial dos futuros orientadores. Pensar uma agenda de formação nessa direção contribuiria para que os orientadores passassem por uma aprendizagem de domínios específicos relativos a: fazer pesquisa, saber ensinar a fazer pesquisa e produzir conhecimentos, e saber interagir em um processo compartilhado e colaborativo de desenvolvimento de pesquisas e construção de conhecimentos. Assim, a docência na pesquisa e a pesquisa na docência, na pós-graduação, teriam um papel importante na formação de quadros de pesquisadores que aprendem a ensinar e de docentes que aprendem a pesquisar.

\section{REFERÊNCIAS}

ARAUJO, G. L. O caminho contraditório da profissionalização docente para a nova geração universitária. Revista Brasileira de Estudos Organizacionais, v. 2, n. 2, p. 196210, dez. 2015.

AZEVEDO, M. L. N.; OLIVEIRA, J. F.; CATANI, A. M. O Sistema Nacional de Pós-graduação (SNPG) e o Plano Nacional de Educação (PNE 2014-2024): regulação, avaliação e financiamento. RBPAE, v. 32, n. 3, p. 783-803 set./dez. 2016.

BARRETO, F. C. S.; DOMINGUES, I. O PNPG 2011-2020: os desafios do país e o sistema nacional de pós-graduação. Educação em Revista, Belo Horizonte, v. 28, n. 3, p. 17-53, set. 2012.

BIANCHETTI, L. Formação de docentes e pós-graduação: docente ou pesquisador? Há futuro para esse ofício? Educação Unisinos, v. 16, n. 3, p. 272-279, set./dez. 2012. 
BONADIMAN, H. L.; ROMAGNOLI, R. C. Socialização profissional de professores universitários iniciantes: uma revisão. Educação Unisinos, v. 21, n. 3, p. 297-305, set./ dez. 2017.

BRASIL. Ministério da Educação. Coordenação de Aperfeiçoamento de Pessoal de Nível Superior. V Plano Nacional de Pós-Graduação (PNPG) 2005-2010. Brasília: CAPES, 2005.

BRASIL. Ministério da Educação. Coordenação de Aperfeiçoamento de Pessoal de Nível Superior. VI Plano Nacional de Pós-Graduação (PNPG) - 2011-2020. Brasília: CAPES, 2010.

CAFÉ, A. L. P.; RIBEIRO, N. M.; PONCZEK, R. L. A fabricação dos corpos dóceis na pós-graduação brasileira: em cena o produtivismo acadêmico. Encontros Bibli: revista eletrônica de biblioteconomia e ciência da informação, v. 22, n. 49, p. 75-88, maio/ ago. 2017.

FREITAS, M. F. Quintal de. Docência, vida cotidiana e mundo contemporâneo: que identidades e que estratégias de sobrevivência psicossocial estão sendo construídas? Educar em Revista, Curitiba, Especial, p. 137-150, 2003.

HOSTINS, R. C. L. Os Planos Nacionais de Pós-Graduação (PNPG) e suas repercussões na Pós-Graduação brasileira. Perspectiva, Florianópolis, v. 24, n. 1, p. 133-160, jan./ jun. 2006.

KUENZER, A.; MORAES, M. C. M. Temas e tramas na pós-graduação em educação. Educação \& Sociedade, Campinas, v. 26, n. 93, p. 1341-1362, set./dez. 2005.

LEITE, J. L. Publicar ou perecer: a esfinge do produtivismo acadêmico. Revista Katál., Florianópolis, v. 20, n. 2, p. 207-215, maio/ago. 2017.

MANCEBO, D. Trabalho docente: subjetividade, sobre implicação e prazer. Psicologia: Reflexão e Crítica, v. 20, n. 1, p. 74-80, 2007.

MAUÉS, O. Trabalho e formação educacional de professores do ensino superior. Tópicos Educacionais, Recife, v. 21, n. 2, p. 75-102, jul./dez. 2015.

MILLS, C. Wright. Sobre o artesanato intelectual e outros ensaios. Trad. Maria Luiza X. de A. Borges. Rio de Janeiro: Zahar, 2009.

RIBEIRO, D. B. Os planos nacionais de pós-graduação: qual a direção dada à produção de conhecimentos no Brasil? Revista Libertas, Juiz de Fora, v. 16, n. 2, p. 37-60, ago./dez. 2016.

RUZA, F. M. Trabalho e subjetividade do professor da pós-graduação da UNESP: o sentido do trabalho e as relações entre sofrimento e prazer. 2017. Tese (Doutorado em Educação) - Universidade Federal de São Carlos, São Carlos, 2017.

SILVA JÚNIOR, J. R.; SGUISSARDI, V. Universidade Pública Brasileira no Século XXI. Educação superior orientada para o mercado e intensificação do trabalho docente. Espacio Blanco, Serie Indagaciones, v. 23, n. 1, p. 119-156, jun. 2013. 
SILVA JÚNIOR, J. R.; SGUISSARDI, V. Trabalho intensificado nas federais: Pós-graduação e produtivismo acadêmico. São Paulo: Xamã, 2012.

SOUZA, J. et al. Prática da pesquisa em grupo: um relato de experiência na área de educação musical. In: ENCONTRO ANUAL DA ABEM, 14., 2005. Anais..., Belo Horizonte, 2005, p. 1-9.

Texto recebido em 17 de maio de 2018 . Texto aprovado em 17 de julho de 2018. 